\title{
The Gendered Implications of Corporate Value Change
}

\section{Gail Hebson* and Annette Cox}

Using case study evidence of a local authority and a building society this article explores the gendered implications of corporate value change programmes and how these are mediated by the types of equality agendas in place at the organizational level. The article explores the gendered impact of new corporate values by identifying how the organizations' changing approach to selection and career development has unintended gendered consequences, affecting different groups in the organization depending on the specific department they are working in and their seniority. As the two organizations follow different equality agendas the data allow us to show the ways in which specific approaches to equality in organizations both shape and are shaped by corporate value change programmes. It is argued that corporate value change programmes have uneven gendered implications, depending on the specific context in which they are introduced and in particular, the ways in which managers and employees make sense of these by both rejecting and reinforcing existing equality agendas already in place.

Keywords: corporate value change, equal opportunities, gender equality, managing diversity

\section{Introduction}

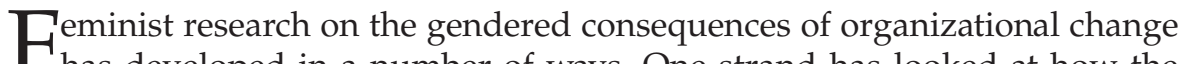
Thas developed in a number of ways. One strand has looked at how the structural changes in organizations can reduce opportunities for women (Beynon et al., 2002; Woodall et al., 1997). Delayering and downsizing has been shown to both eradicate many of the middle management roles where women had achieved success by creating broader and more generalist

Address for correspondence: *Manchester Business School (East), University of Manchester, Booth Street West, Manchester, M15 6PD UK; e-mail: gail.hebson@manchester.ac.uk

This article was published online on Jan 19 2010. An error was subsequently identified. This notice is included in the online and print versions to indicate that both have been corrected on Mar 242010. 
managerial roles and reducing the functional chimneys women had used to progress in organizations (Woodall et al., 1997). Organizational cultures in changing organizations have also been a central theme in debates. The growing importance of informal networks and cultures have been identified as new conduits for perpetuating gendered inequality (Dickens, 1998). Long hours cultures that reward face time and the shift from a time-based employment contract to one that is result-based (Rubery et al., 2005) are particularly pervasive in times of organizational change and have been shown to be the manifestations of deep-rooted gendered cultural values about what constitutes the ideal worker and the equation of time with productivity (Lewis, 1997; Rapoport et al., 2002). Organizational change and concurrent shifts in equality policy have also been a key focus in feminist research on organizational change. Connections have been made between the individualistic tendencies of much organizational change and the direction of equality policies. A shift from equality policies that follow a traditional equal opportunities approach to ones that use the language of managing diversity echoes the increasingly individualistic approach to the management of people in organizations, and while there are many overlaps with contemporary human resource management (Kirton and Greene, 2005) there are worries about the 'market oriented definitions of diversity' that can emerge (Wajcman, 1998; Webb, 1997, p. 164).

There is much less analysis of the gendered nature of corporate valuesbased change programmes. At one level this is understandable as, compared with the organic nature of organizational culture, they are deemed to be superficial. Managerialist as they are in orientation, Martin (2002) argues they are interpreted as corporate propaganda which is not shared by organizational members. However, although corporate culture and value change programmes are not necessarily reflective of the core beliefs and values in an organization, they can nevertheless be a productive way to explore newer, more subtle processes of gendering taking place in changing organizations.

Using case study evidence of a local authority and a building society, this article explores the gendered impact of new corporate value change programmes by identifying how they are manifested in concrete ways in the organizations' changing approach to selection and career development. It will be argued that such change programmes have unintended gendered consequences, impacting differently on different groups depending on their location in the organization. It will be shown that the gendered implications of corporate value change programmes are mediated by the types of equality agendas in place at the organizational level.

Furthermore, a focus on the interaction between such value programmes with specific equality agendas reveals how equality agendas are themselves in a state of flux. Our evidence supports recent research that has highlighted the problem of categorizing equality policies as either equal opportunities or as managing diversity (Dickens, 2005; Foster and Harris, 2005). 
The structure of the article is as follows. We firstly discuss some of the debates surrounding the nature of corporate value change programmes and the research that has engaged in this from a gendered perspective. We then go on to discuss the connections between these culture and value change programmes and two areas of human resource practices; selection and career development. It is argued that while much feminist research has been conducted on the gendered nature of these areas of organizational practice, little has examined how they are influenced by corporate cultural change programmes and how this contributes to new forms of gendering. By focusing on the impact of corporate value change on areas of HR policy and practice it is possible to uncover the gendered aspects of corporate value change programmes without making unwarranted and untestable assertions about whether organizational members believe in the rhetoric of management values or not.

Some of the debates surrounding the shift from an equal opportunities to a managing diversity approach are also explored, and it is argued corporate value change programmes shape and are shaped by the equality agendas in place in organizations. We then go on to discuss the two case study organizations, identifying some sectoral characteristics that form the backdrop to the specific organizational changes we identify in the two cases. The methods of data collection are then summarized, and this is followed by the findings section organized around the themes of changing selection and changing careers. We conclude by drawing out some of the key themes of the research, highlighting the ways in which corporate value change programmes have gendered implications, not least because of the ways they interact with equality agendas in specific organizational contexts. We argue that the impact of corporate values is uneven across organizations, and also discuss how corporate values programmes can be a useful device to explore more deep-rooted gendered values and cultures in organizations.

\section{Corporate culture and value change programmes}

Research on corporate culture and values starts with an awareness of its managerialist orientation. Corporate culture is used to describe a set of 'cultural values, norms and their symbolic manifestations, devised by management and transmitted, both formally and informally, to the rest of the workforce' (Turner, 1990, in Hancock and Tyler, 2001, p. 100). Management attempts to introduce and instil a specific corporate culture or value programmes have led to a number of avenues of research. The link between strong corporate cultures and organizational performance strongly advocated by Peters and Waterman (1982) has set the scene for much subsequent research. One strand focuses on the conditions that need to be in place for a strong corporate culture to be established and bring about improved organizational performance (see Cheyne and Loan-Clarke, 2009, for an overview). 
Other research focuses on resistance to corporate culture and values, showing how the acceptance and rejection of managerial attempts to instil corporate culture will depend on the existing subcultures already in place (Harris and Ogbonna, 1998).

Explorations of organizational culture have critiqued the notion of culture as a variable to be manipulated through attempts to change values (Alvesson, 1993; Legge, 2004; Smircich, 1983). An appreciation of this has led many to unpack the concept of organizational culture and values and identify the different levels at which they operate. Schein (1985) distinguishes between three layers of culture; firstly artefacts that constitute the surface level behaviour and physical manifestations of culture; secondly, values that are the attitudes that can be easily communicated and thirdly, basic assumptions, which are the deep-rooted and often take-for-granted assumptions that shape attitudes and behaviour. Corporate values fit into the second layer. They are a sense of what ought to be (Ogbonna, 1992) and can reveal what is deemed appropriate or inappropriate in the organization. While Schein's work has been critiqued for assuming an unrealistic level of consensus across the organization (Callan, 2007, p. 676) it nevertheless provides a useful framework for the study of corporate value change programmes as it recognizes they are distinct from the base assumptions in the organization and thus may not accurately reflect the organizational culture or values shared by most organizational members. An appreciation of the different levels at which culture operates has led some to argue that the most organizations can hope for is a change in behaviour in accordance with new cultures and values, as opposed to a shift in core beliefs held by organizational members (Ogbonna, 1992). Thus 'the culture that may be managed is the manifestly observable behaviours not the unobservable deep-seated attitudes of individuals' (Ogbonna, 1992, p. 82). However, Schein (1985) shows how these more surface level values and forms of behaviour can also reveal deeper basic assumptions. As Martin (2002) argues, 'what is important is not the cultural manifestation but how people interpret it' (Martin, 2002, p. 47). Thus, in our study corporate values became significant because they were interpreted and encouraged behaviour in ways that had gendered implications.

It is this pragmatic approach that has shaped our analysis of the impact of corporate value change programmes in the two case study organizations. When studying corporate value change programmes we recognize their managerialist orientation and do not assume they reflect the internalized values and beliefs of organizational members. We hope to add another dimension to existing research that looks at corporate value programmes from a gendered perspective. Research on gender has studied the masculine nature of corporate rhetoric and values and has explored this through linguistic analysis (see Halford and Leonard, 2001, for an overview,). The gender blindness of organizational cultural change programmes has also been critiqued (Helms Mills, 2005). Yet there have been few discussions of how 
corporate value change programmes have concrete gendered implications, because of their potential interactions with equality agendas. Woodall, et al. $(1997$, p. 10) is a notable exception, showing how equal opportunities policies and cultures were overshadowed by corporate culture change programmes. Halford and Savage (1995) have also used case study research to show how people accept and reject specific value change initiatives in gendered and non-gendered ways.

We aim to build on this by connecting some of the recent feminist debates relating to selection, careers and equality policies and show how a gendered perspective on corporate cultures and values can add another dimension to this research.

\section{Gendered practices: selection and careers}

Changing organizational practices in relation to selection and careers have been linked to management-initiated culture change (Cheyne and LoanClarke, 2009). Selection practices are argued to be particularly important, as Ogbonna (1992) states: 'Selection is probably the most widely cited HRM policy that facilitates the management of culture' (Ogbonna, 1992, p. 81). The traditional person-job fit approach simply considered how suitable the individual was for the post rather than how acceptable they were (Jewson and Mason, 1986). This has, to some extent, been replaced by recruitment based on attitudes and values. Wickham [Correction made here after initial online publication.] et al. (2008) argue that 'What matters is the whole person, and the extent to which they will fit into the company and contribute to it' (Wickham [Correction made here after initial online publication.] et al., 2008, p. 212). Dickens (1998) argues this increasing use of acceptability criteria, often using attitudinal characteristics to select candidates, may exacerbate discrimination in selection as acceptability criteria interacts with gendered stereotypes (Dickens, 1998, p. 29). The separation of suitability and acceptability was never straightforward in practice (Webb, 1997) but the shift to acceptability criteria is more pervasive in organizations that use corporate values programmes to support organizational change, requiring employees to demonstrate they match the organization's culture (Cheyne and Loan-Clarke, 2009, p. 254).

Connections between feminist debates relating to gendered careers and the impact of corporate value change programmes on career development can also be further explored. Ogbonna (1992) argues that training and development are central to the management of corporate culture and values as the internal promotion policy can be selective and reinforce company culture by rewarding those who display behaviour consistent with these values (Ogbonna, 1992, p. 81). However, he uses his case study research to reveal the contradictions that emerge between this approach and the company desire to recruit externally, thus increasing the potential of diluting a strong company culture. 
Research on gendered careers in organizations has not focused on corporate values but has rightly emphasized how the more deep-rooted basic assumptions in organizations perpetuate gendered disadvantage. Basic assumptions relating to what constitutes the ideal worker and whether flexible careers are an entitlement or a perk have been identified as key aspects of organizational culture that perpetuate gender inequality (Rapoport et al., 2002). Callan (2007) shows how in times of organizational change any other cultural assumptions that could act as a challenge to these basic assumptions are overridden and only if cultural change is crucial to the company's survival will such root cultural facets change (p. 686). It is interesting to see how a focus on more surface level corporate values map onto such root basic assumptions about gender. In both case study organizations corporate values have been introduced as part of a modernizing agenda and in this sense are part of a strategy of survival. Do the organization's new corporate values reveal the basic gendered assumptions in the organization and do they challenge or reinforce them in any way? In this sense corporate value change programmes can be another way to interrogate the gendered implications of deeper cultural assumptions in the organization.

An understanding of how these processes are manifested in specific organizational contexts also requires an appreciation of how corporate value change programmes shape and are shaped by the equality agendas in place in organizations. Research on equality agendas have charted a shift from equal opportunities to managing diversity (see Kirton and Greene, 2005 for overview) and the relative strengths and weaknesses of each can be assessed by the potential of each approach to challenge the deep rooted cultural assumptions that have been shown to perpetuate gender disadvantage. The group-based equal opportunities approach has been criticized because of its reliance on a procedural formula (Webb, 1997, p. 160) and for its failure to erode organizational structures and cultures based on male patterns of working (Liff and Cameron, 1997). In contrast, optimistic accounts of managing diversity recognize its potential to engender cultural change by disrupting the norm of the typical employee (Liff and Cameron, 1997). However, concern is expressed that this radical potential fails to materialize because of the precarious business case on which it rests and the dominance of the individualistic strain of managing diversity that fails to recognize the power differences between men and women (Wajcman, 1998). The overlaps between the two approaches characterize recent research findings (Foster and Harris, 2005) and, indeed, in theoretical assessments of the two approaches the overlaps were always recognized (Liff, 1997). By exploring corporate change programmes some of the ways this convergence comes about in practice is revealed. In particular, it is possible to show how equality agendas are shaped by specific organizational change agendas (including value change) rather than abstract principles relating to equal opportunities or diversity. 


\section{Methods}

Our data are taken from two case studies of the gendered impact of organizational change in the north-west of England which were part of a larger research project. We draw on evidence from two sectors with high levels of female employment - local government and financial services. In both local government and financial services, widespread sectoral changes have been important in reshaping organizations. In financial services, continued sectoral consolidation, the rise of generalist organizations offering diverse products across the full spectrum of financial services through new channels such as call centres and the Internet and competition from companies outside the sector, such as supermarkets, have focused organizational attention on cost reduction and improved customer service (Morgan and Sturdy, 2000). This has involved significant changes in the work organization of staff, including demands for knowledge of a wider range of products, extended hours of service delivery and the use of 'soft' customer management skills. Our case study organization is illustrative of these changes. Financeco had become a major player in the market with an exceptional performance in the year ending 2004. The company had invested in the introduction of a new information technology system and introduced a lending processing centre and contact centre, making full use of call centre technology. Cultural change was central to the change agenda in the form of a values-based organizational improvement programme implemented in 2003. The purpose of the programme was to ensure consistency of behaviour across all employees around a number of values and givens. These values were promoted through a number of roadshows, instilled through development interventions and workbooks that all staff were required to use, and formed part of the criteria for appraisal. A new diversity policy introduced in 2003 capitalized on some of the corporate values and was based on a business case argument: 'To improve business performance through an integrated approach to attracting and retaining employees and customers from diverse, potential sources' (Financeco documentation). Human resource (HR) managers argued that this was mainstreamed throughout the operational policies and highlighted how it was intended to support the corporate strategy directly. In particular, the value of 'Being a good place to work, grow and develop' was flagged up in interviews with HR managers as encompassing the organization's commitment to diversity. The company was a member of Opportunity Now, an organization in the UK that represents employers who are committed to including women fully in the workplace. The shortage of women in senior management was recognized and a women's development programme was put in place to address it.

For local councils, government policy and reform during the 1990s has brought greater emphasis on obtaining efficiencies in service delivery through the introduction of marketization principles. These involve 
benchmarking performance and creating choice between service providers through contractual approaches to public service delivery as part of the new public management approach (Ferlie et al., 1996). The 1999 Local Government Act put in place initiatives such as the best value regime, which called for local authorities to 'make arrangements to secure continuous improvement in the way (their) functions are exercised, having regard to a combination of economy, efficiency and effectiveness' (quoted in Martin, 2000, p. 211). Its emphasis on economy means that cost-competitiveness is paramount in measuring performance, despite some more participative elements and focus on the quality of service that differentiate it from previous Conservative government reforms (Martin, 2000).

Both the social care and housing departments visited in Cityco were experiencing changes resulting from the effects of government corporate assessment and best value regimes. Local housing offices were replaced with a call centre supplemented by local services teams. The arrival of the call centre brought an influx of more sales-focused staff with little knowledge of housing. Managers were preparing for the transfer of council homes to an external organization to help meet the government target that all of Britain's council housing should reach the 'Decent Home Standard' by 2010. In the social services department a major change had recently been implemented that involved widening the remit of the previous social services department to include Early Years and Play and Youth Services. The department had therefore grown substantially and also included a greater proportion of parttime workers than it had done in the past. The department was continually responding to new government initiatives. The National Care Standards, the Supporting People initiative and the government initiative, 'Every Child Matters', in particular, were all mentioned as driving forces of change. Our interviews cut across a number of services in the department, including social work, homecare and older people services, day-care services and residential care. While the department had not outsourced its services, the council's share of the market had significantly decreased in areas such as home care, as it concentrated on becoming a niche provider of a more specialized service. There had been the introduction of a one-stop shop, the Contact Service for Social Care, using call centre technology to establish a single point of contact for all initial enquiries to the department.

The introduction of a new performance culture driven by the government's corporate performance assessment was highlighted as the key cultural change by managers. Cityco had created new sets of corporate objectives and values to support its focus on performance. Being people-focused was the key objective and concerned council efforts to improve customer service. The value of 'valuing employees' was expressed in terms of their contribution to the organization, with a commitment to 'support and encourage their development in working hard to deliver better services' (Cityco documentation). All these values were linked to service delivery which, in turn, was linked to 
meeting performance objectives. Despite the adoption of the new values, Cityco made no changes to its longstanding equal opportunities policy for managing gender inequality. Equal opportunities policies were centralized through the personnel department and Cityco was committed to achieving the Equality Standard, a national guidance framework produced by the Employers' Organisation for Local Government.

The data presented are drawn from semi-structured interviews lasting between 60 and 90 minutes conducted with 62 individuals. Interviews were conducted with samples of approximately 15 men and 15 women from each organization across a range of positions, selected to gain views from individuals at different stages of their careers, different levels of seniority and working in different parts of the organization. These were supplemented by interviews with two HR staff (including the diversity officer at Financeco) at both Cityco and Financeco, who gave an overview of change initiatives and equality and diversity policies. A breakdown of the number of interviews by hierarchical level is given in Tables 1 and 2. The profile of the samples was strikingly different in terms of their length of service in the organization. A total of 19 interviewees in Cityco had worked at the local authority for 15 years or more, including most senior managers, although three new senior managers had been recently recruited to implement change in the social services department. Six out of ten frontline staff (including social workers and housing case workers) had worked in the local authority for approximately 2 years. A contrasting profile was found in Financeco. Half of the

Table 1: Interview sample by level of seniority: Cityco

\begin{tabular}{|lllc|}
\hline & $\begin{array}{l}\text { Senior } \\
\text { managers }\end{array}$ & $\begin{array}{l}\text { Middle } \\
\text { managers }\end{array}$ & $\begin{array}{l}\text { Frontline } \\
\text { employees }\end{array}$ \\
\hline Men & 4 & 7 & 3 \\
Women & 7 & 2 & 7 \\
Total & 11 & 9 & 10 \\
\hline
\end{tabular}

Table 2: Interview sample by level of seniority: Financeco

\begin{tabular}{llll|}
\hline & $\begin{array}{l}\text { Senior } \\
\text { managers }\end{array}$ & $\begin{array}{l}\text { Middle } \\
\text { managers }\end{array}$ & $\begin{array}{l}\text { Frontline } \\
\text { employees }\end{array}$ \\
\hline Men & 6 & 3 & 4 \\
Women & 4 & 5 & 9 \\
Total & 10 & 8 & 13 \\
\hline
\end{tabular}


interview respondents had worked at Financeco for less than 5 years and only three had worked there for more than 15 years (only one of the latter was a senior manager).

The interview topics focused on the respondents' experiences of recruitment, training and promotion, working time choices and their knowledge and use of equality policies as well as values-based change. The interviews were conducted between November 2003 and July 2004, taped, transcribed, and analysed manually by constructing data matrices that enabled the data to be compared and contrasted within and across organizations, using both key themes and levels of hierarchy as organizing principles of comparison. While the data were collected before the current recession we feel confident that the processes we reveal relating to the implementation of corporate value change and its gendered implications are still relevant. As Callan's (2007) research shows, the success of attempts to bring about cultural change is often dependent on whether a change in culture is part of the survival strategy of the organization. In the current climate, corporate value programmes may become the focus of survival strategies and in such a context the tensions we found between such programmes and equality policies may become heightened to an even greater extent.

\section{Findings}

\section{Changing values and gendered selection}

In both organizations there had been a shift to values-based recruitment. For Financeco, seeking applicants who shared the organizations' values was central to the recruitment process and these values were argued to be more important than recruiting people with technical skills. The managers who had been involved in recruitment repeatedly talked of the need to 'live the values', especially those of customer service and taking personal responsibility. The rationale for the shift to value-based recruitment was that, although the organization could teach technical skills, people's values and the behaviour that led on from these were far less malleable:

The feeling is, you can't change easily people's behaviour and values. So it is no good having a really, really highly technical person if they exhibit all the wrong behaviour. (Senior manager 2, female, Financeco)

The HR manager went on:

One of the things is to make sure the people we bring into the organization are absolutely aligned to those values because that will give us a quantum shift in terms of having people in the organization who are inclined to behave in the right way. (Senior manager 1, female, Financeco) 
The manager connects values and behaviour and this was central to the corporate value change programme. In Financeco there were right ways to behave and, by implication, wrong ways to behave. In particular, all management interviewees identified the critical behaviour for organizational success to be that of putting the customer first and of taking personal responsibility. We shall see in the discussion of careers that this has gendered implications that disadvantage women but, in relation to the recruitment stage, it is difficult to say whether men or women were disproportionately affected, as both are capable of impression-managing in ways that give off the right messages about their values and behaviour. Those interviewed who had been recruited in the previous 2 years spoke of the values more than those who had been in the organization longer, but no gender difference was evident. However, the gendered implications of the changing selection practices were pervasive, albeit indirect and unnoticed, as they undermined the more radical potential of Financeco's diversity aims. Insisting that all employees share homogeneous values is inconsistent with an equality agenda intended to promote diversity. It is blind to the ways in which group membership, relating to gender or any other form of difference, might result in employees holding contrary values that would be objectionable.

While values-based recruitment was uniformly accepted in Financeco, its implementation created tensions for some managers in Cityco because of an understanding of how it conflicted with well-established equality agendas. A debate was taking place over whether Cityco should be evaluating applicants' job-specific skills or their personal qualities. A personnel officer responsible for recruitment in Cityco describes the difference between the past prescriptive approach and the new approach, where rigid job specifications were relaxed and recruitment panels were given more flexibility in terms of the questions they could ask:

The way that it used to be run was very prescriptive, there was a set guidelines, and the new one is set up to put more of an onus on panels to be a little bit more bespoke. (Frontline administrator 5, male, Cityco)

The criteria for assessing what people could bring to the job invariably related to personal characteristics of drive, attitude and sharing the new values. The response below is typical of what managers described they were looking for in new recruits:

We've brought in corporate values and we've tried to advertise jobs and sell them and then test people and recruit people on the basis of values and attitudes. We don't want people to know about housing, for housing officers, I am not really interested in whether they have housing, it's whether they've got the right attitude. (Senior manager 4, male, Cityco)

There was no evidence that the new values were used to discriminate directly against one gender or another when recruiting. However, there was some 
evidence of potential for indirect discrimination in enhancing the discretion of those involved in the recruiting process. Two female senior managers in the Social Care department were recruited by head hunters who used initial informal interviews to test how well they would fit into the team before the candidate reached the formal interview stage. When managing and implementing organizational change, the dynamics in the senior management team were regarded as crucial and therefore using the new process to select the right candidate was accepted as legitimate. This was even the case for another senior female manager who believed that her job application was unsuccessful because the male manager with whom she would have to work closely felt more comfortable with men:

I don't think it was skills and abilities, I think it is male attributes. They feel more comfortable with men.... we have this strict recruitment process saying you have to be equal at all times but at more senior levels I think we have to recognize that a senior manager wants someone they can be able to work with. (Senior manager 9, female)

In Cityco this new shift to values-based recruitment and a focus on team fit conflicted with the equal opportunities policy. As the example above shows, perceptions of group membership - specifically what it is like to work with either a woman or a man - can determine this. Interestingly, this was more so the case in the Social Care department where change has been particularly pervasive. Davies and Thomas (2002) argue the changes imposed on social services have created a climate which encourages 'a model of management which encompasses competition and change, [and] is achievement orientated and based on control' (Davies and Thomas, 2002, p. 469). The drive to implement change effectively appeared to override other values in the organization, such as a traditional equal opportunities approach to recruitment.

In contrast, in the housing department there were voices of dissent that challenged values-based recruitment. These managers had worked in Cityco for a long time, were committed supporters of equal opportunities policies and preferred traditional person-job fit recruitment criteria. These accounts are markedly different from the approach advocated by the recruitment officer quoted above and the managers recognize that this contradicts the current management discourse around recruitment;

Not sure I like the word characteristics [when recruiting] I look for skills I am afraid ... I suppose it is a long time exposure to a particular way of recruiting in the City Council. (Middle manager 6, male, Cityco)

Because we have an equal opportunities policy, what we are looking at is specific skills against a job specification and my role as an interviewer is to test out and find the person who meets those requirements so the quality depends on the person spec. (Middle manager 8, female, Cityco). 
While at Financeco and in the social services department of Cityco there was no recognition of any potential adverse implications of using value-based recruitment, in the housing department of Cityco this coexisted uneasily with the longstanding use of an equal opportunities approach and created tensions for some managers. This is an example of how responses to corporate values can reveal some of the basic assumptions held by employees as we see how organizational members interpret values-based recruitment in ways that either reinforce or reject existing equality agendas.

\section{Changing values and gendered careers}

Policies around internal progression in organizations can be used as a key way to communicate to employees what types of behaviour and values are needed for promotion (Ogbonna, 1992). It is possible to explore the concrete gendered implications of this by assessing whether this affected men and women in different ways and whether any adverse impacts were due to an undermining of existing equality agendas.

In Financeco, we found that the corporate values programme and its emphasis on customer responsiveness and taking personal responsibility had a major impact on some women's careers in particular parts of the organization. The customer-related parts of the organization were at the heart of the organizational change process; structural changes had led to a new contact centre and a new lending process centre and the value change programme was driven by putting the customer first. In reality, this meant that those working in customer-related parts of the business, who were predominantly women, were unable to capitalize on the potential working-time flexibility on offer in the organization's diversity policy. One customer service manager described her 'choice' of remaining full-time when her request for part-time working was refused. She recognized that women are affected by family commitments more than men but had no expectation that Financeco should accommodate this to promote gender equality and she withdrew her request after feedback from her manager:

You can do my role as long as you're full time. For people with young families it's more difficult, which would tend to impact on women more than men. My own experience is that 6 months ago, I made a request to reduce my hours maybe to 4 days as opposed to 5 and I couldn't do that in the department that I was working in. I could do it in the same role in a different department, but I felt it wouldn't be as challenging, so I decided to take the choice to stay where I was and continue to work full time. (Middle manager 11, female, Financeco)

However, there was support in some parts of the organization for flexible careers at the senior levels of the organization. A senior female manager in the HR department had recently been promoted into a part-time role after 
returning from maternity leave after the birth of her third child. She had questioned whether it was possible to do the role on a part-time basis and found that the encouragement of her manager persuaded her to try out the new contract:

I said, 'I can't because I'm not prepared yet to do full-time work, because I've got babies, you know, I'll wait till they're a bit bigger then I'll come back. And I don't think it's a role that can be done ... part-time'. And she said to me, 'Well, sleep on that and think about the structure of your team and how you might organize that'. She was incredibly supportive [and] said we need to be leading by example. (Senior manager, female, Financeco)

The disparity between different parts of the organization was hidden behind the overriding value of taking personal responsibility. The HR manager reported that 35 out of 37 requests (most made by women) for flexible working had been fully or partly met but emphasized that staff should request this responsibly:

We also put the onus on the individual to think about if you want to change your working patterns ... think about what the business impact will be and how you will solve that. (Senior manager 1, female, Financeco)

From the account of the customer service manager above, it appears the emphasis on personal responsibility had been successful. This individualism appears to dilute any sense of disparity or inequality between men and women or between women in different parts of the business. There were no evidence of flexible career paths being pursued by those working in the customer-focused parts of the business; there were no part-time branch managers and in the newer contact centre team leaders and managers were all women working full time.

However, corporate values could reinforce diversity policies in ways that facilitated more radical equality initiatives, although this only happened if these fitted the business interests. In Financeco the rapid expansion had created a number of new senior roles but it was proving difficult to recruit suitable external applicants. In response, Financeco had sourced a training programme for women called Springboard to encourage their female middle managers to come forward for promotion. The aim of this initiative was to build up the confidence of women, which would tackle both Financeco's recruitment problems and the underrepresentation of women at senior levels. Women who had participated in the programme felt that it had been highly significant in helping them to develop their careers:

I went on a programme we do called Springboard. It is a women's development course, it is not just work related, it sort of affects you at home as well, it is just about self-confidence and knowing that you can achieve anything and just giving us all a bit of a boost really, mainly women 
because I think they were concerned there is not enough women in management levels and things like that, so I went on that and I actually thought yes, I can achieve this. (Frontline employee 1, female)

This employee's account draws out how a group-based initiative was used by women to fulfil individual aspirations. This appeared to work well in Financeco because it was a version of diversity that recognized group interests while also encouraging women to feel confident enough to take individual responsibility. In this example, the corporate values and the diversity agenda reinforced each other with positive gendered consequences. While we are unable to say whether the women who participated were chosen because they displayed values and forms of behaviour consistent with the corporate value change programme, the data do show how the value of taking personal responsibility could allow people to take up group-based initiatives in ways that avoided such initiatives being stigmatized as special treatment.

In Cityco a similar uneven picture emerged. The best value agenda had placed responsiveness to the customer at the centre of change but this had implications for the careers of frontline staff, who are predominantly women, working in these parts of the service. Both departments had created contact centres using call centre technology where administrative staff were on call to answer a wide range of queries from the public. Staff recruited for these roles had experience in customer-service jobs and managers acknowledged there were no planned career routes for those in these roles. In the past administrative staff built up knowledge in a specific specialism, such as housing, to develop future careers as housing officers, but in the contact centres there was no opportunity for such development. For those in traditional frontline roles in both departments, such as housing officers or care and residential workers, the primacy accorded to the customer had created tensions with the equality agenda. Managers struggled with the issue of serving the customer and valuing employees by offering them working time flexibility. We were told that some requests for flexible work were unsuccessful because they did not fit the needs of the service. In both departments that we visited some managers were uncomfortable about prioritizing customer service over valuing staff:

I think the authority is in danger ... of going too far over one side and forgetting its other responsibilities towards the staff ... there are some hard choices that we have to make as an organization. (Senior manager 9, female, Cityco).

While some of these jobs, such as residential carer, are not necessarily career jobs in the traditional sense, such jobs have provided those with few qualifications with secure employment in which there is some opportunity for advancement. By curtailing options for flexible working time in such jobs Cityco could be indirectly curtailing the opportunities of many low-paid 
women, as they choose to move to jobs in the less protected private sector (particularly in social care) and swap security and better pay for the flexibility they value.

Another finding that also indirectly reveals the subtle forms of gendering taking place in Cityco emerged in discussions of long hours working. Senior managers emphasized a culture of getting results rather than long hours working, but with increased workloads at all levels of the organization, in practice this led to long hours working. Managers argued an informal flexible approach was being adopted where periods of long hours working or working unsocial hours was compensated by flexibility at other times:

It is very flexible. I know that from my managers I get what is needed to produce the results, then if someone rings me and says can I have the afternoon off at fairly short notice people cover for each other, it's very flexible really, it is not a problem ... so we have not got formalized flexible working arrangements with anyone. (Senior manager 4, male, Cityco)

The themes in this account were present in many of the interviews with senior managers. If people were getting results they would be given flexibility at senior levels. Yet this flexibility was less visible to less senior staff. Two women middle managers had self-selected themselves out of promotion due to their perception that long hours were required for senior roles and this was incompatible with their family life. The gendered implications of this new informal approach went unnoticed. Worryingly, the sense of entitlement that is often found in the public sector and is thus more likely to lead to more men taking up equality policies appeared to be undermined by a corporate change programme based around service delivery to meet performance objectives.

\section{Discussion and conclusions}

A difficulty when researching the impact of values is trying to disentangle the difference between 'talk and practice' (Halford and Leonard, 2006, p. 672). It can be risky for interviewees to reveal that they do not 'believe' in corporate values to an unknown interviewer. Thus we have tried to move away from a discourse analysis of mangerialist discourses that focuses on what they represent and instead explore what they do (Reed, 2000, p. 529) by looking at concrete ways change manifested itself in relation to selection and careers in ways that had gendered implications.

The article has aimed to explore some of the concrete ways corporate value change programmes have gendered implications, not least because of the ways they interact with equality agendas in specific organizational contexts. By focusing on how corporate value change programmes shaped practices relating to selection and careers, the article has highlighted some of the new 
subtle forms of gendering that are taking place in organizations, and has shown that although such values may not reflect the deep-seated values of the employees in an organization, they are nevertheless likely to help shape the organization's degree of diversity and its implementation of equality policies.

A gendered perspective on corporate values was revealing in three ways. Firstly, the nature of each organization's equality policies and the commitment to them is evident in the discourse around values. We found evidence that increased discretion and flexibility enters the selection process when corporate values are used as a selection principle. This is regardless of whether the organization follows an equal opportunities approach or a managing diversity approach. As Callan (2007) found, it is the survival of the company that shapes the equality policy in place and thus, in parts of Cityco, we found the new organizational emphasis that senior managers must fit in personally with the team threatened the traditional equal opportunities goal of judging all individuals solely according to their skills. In Financeco there was no recognition that values-based recruitment undermined the aim of an equality policy that was trying to harness workforce diversity. However, there were occasions when equality agendas and corporate values appeared to reinforce each other. In Financeco the women-only training programmes were an example of a group-based version of diversity that did not exist elsewhere in the organization, either in policies or in people's beliefs. This was successful for two reasons; from the perspective of the participant it merged together individualist and group-based interpretations of careers and from the perspective of the business it resolved recruitment problems. This is an example of how complementarities between corporate value change and equality agendas can have positive gendered consequences in terms of careers.

Secondly, the interactions between values programmes and equality policies reveal the uneven nature of the gendered implications of organizational change. The article has reinforced Halford and Leonard's (2006) emphasis on the importance of organizational context in understanding changing organizations. We found different gendered implications of change for different groups of workers in these organizations. In Financeco, those working in the customer-related parts of the business experienced the brunt of change whereas in Cityco, those working in social care, particular frontline staff, were particularly affected by a performance-based culture.

This leads on to a final theme that relates to whether it is possible to use such managerial values as a vehicle to explore some of the more deeprooted cultures and values in organizations that perpetuate gender disadvantage. To do this it is necessary to engage with the debate as to whether organizational members use such values to interpret their experiences and shape their behaviour. Our findings support existing research that shows how both employees and managers filter understandings of new corporate values through existing values and cultures (see Harris and 
Ogbonna, 1998). Thus, managers and employees make sense of new corporate values in ways that both reject and draw on existing equality agendas already in place. This is crucial to understanding the gendered nature of corporate value change and also how corporate change mediates the equality policies in place.

Future research that takes a gendered perspective on corporate value change, and organizational change more generally, needs to explore how significant the acceptance and rejection of such values are in perpetuating the more subtle processes of gendering taking place. By focusing on specific aspects of employment policy it is possible to monitor how values have concrete gendered consequences, not least because of the way organizational members interpret and react to them. Furthermore, the interaction of corporate values and equality agendas in contexts of change can reveal some of the gendered deep-rooted basic assumptions in organizations. Research on corporate value change programmes can be a useful device to make more explicit some of the deep-rooted gendered values and cultures in organizations and has the potential to reveal the myriad of ways in which existing equality agendas in organizations are both undermined and supported in changing organizational contexts.

\section{Acknowledgements}

The research project was part-funded by a grant from the European Social Fund, which we gratefully acknowledge. We would like to thank Gwen Oliver and Sirin Sung who were researchers on the project. The authors would also like to thank the editors and anonymous referees for their very helpful comments on an earlier version of this article.

\section{References}

Alvesson, M. (1993) Cultural Perspectives on Organizations. Cambridge: Cambridge University Press.

Beynon, H., Grimshaw, D., Rubery, J. and Ward, K. (2002) Managing Employment Change. Oxford: Oxford University Press.

Callan, S. (2007) Implications of family-friendly policies for organizational culture: findings from two case studies. Work, Employment \& Society, 21,4, 67391.

Cheyne, A. and Loan-Clarke, A. (2009) Organisational and corporate culture. In Redman, T. and Wilkinson, A. (eds) Contemporary Human Resource Management, pp. 243-69. Harlow: Pearson Education.

Davies, A. and Thomas, R. (2002) Gendering and gender in public service organization. Public Management Review, 4,4, 461-84.

Dickens, L. (1998) What human resource management means for gender equality. Human Resource Management Journal, 8,1, 23-40. 
Dickens, L. (2005) Walking the talk? equality and diversity in employment. In Bach, S. (ed.) Managing Human Resources, pp. 178-208. Oxford: Blackwell.

Ferlie, E., Pettigrew, A., Ashburner, L. and Fitzgerald, L. (1996) The New Public Management in Action. Oxford: Oxford University Press.

Foster, C. and Harris, L. (2005) Easy to say, difficult to do diversity management in retail. Human Resource Management Journal, 15,3, 4-17.

Halford, S. and Leonard, P. (2001) Gender, Power and Organizations. Basingstoke: Palgrave.

Halford, S. and Leonard, P. (2006) Place, space and time: contextualizing workplace subjectivities. Organization Studies, 27,5, 657-76.

Halford, S. and Savage, M. (1995) Restructuring organizations, changing people: gender and restructuring in banking and local government. Work, Employment $\mathcal{E}$ Society, 9,1, 97-122.

Hancock, P. and Tyler, M. (2001) Work, Postmodernism and Organization: A Critical Introduction. London: Sage.

Harris, L.C. and Ogbonna, E. (1998) Employee responses to cultural change efforts. Human Resource Management Journal, 8,2, 78-92.

Helms Mills, J. (2005) Organizational change and representations of women in a North American utility company. Gender, Work \& Organization, 12,3, 242-69.

Jewson, N. and Mason, D. (1986) The theory and practice of equal opportunities policies: liberal and radical approaches. Sociological Review, 34,2, 307-34.

Kirton, G. and Greene, A. (2005) The Dynamics of Managing Diversity; A critical approach. $2^{\text {nd }}$ edn. Oxford: Elsevier Butterworth-Heinemann.

Legge, K. (2004) Human Resource Management: Rhetorics and Realities. Basingstoke: Palgrave.

Lewis, S. (1997) Family friendly employment policies: a route to changing organizational culture or playing about at the margins? Gender, Work E Organization, 4,1,1323.

Liff, S. (1997) Two routes to managing diversity: individual differences or social characteristics. Employee Relations, 19,2, 11-26.

Liff, S. and Cameron, I. (1997) Changing equality cultures to move beyond women's problems. Gender, Work E Organization, 4,1, 35-46.

Martin, J. (2002) Organizational Culture: Mapping the Terrain. London: Sage.

Martin, S. (2000) Implementing 'best value': local public services in transition. Public Administration, 78,1, 209-27.

Morgan, G. and Sturdy, A. (2000) Beyond Organizational Change: Structure, Discourse and Power in UK Financial Services. Basingstoke: Macmillan.

Ogbonna, E. (1992) Organization culture and human resource management: dilemmas and contradictions. In Blyton, P. and Turnbull, P. (ed.) Reassessing Human Resource Management, pp. 74-96. London: Sage.

Peters, T.J. and Waterman, R.H. (1982) In Search of Excellence: Lessons from America's Best Run Companies. New York: Harper and Row.

Rapoport, R., Bailyn, L., Fletcher, J.K. and Pruitt, B. (2002) Beyond Work-family Balance. San Francisco, CA: Jossey-Bass.

Reed, M. (2000) The limits of discourse analysis in organization studies. Organization, 7,3, 524-30.

Rubery, J., Ward, K. and Grimshaw, D. (2005) The changing employment relationship and the implications for quality part-time work. Labour and Industry, 15,3, 7-28.

Schein, E. (1985) Organizational Culture and Leadership. San Francisco, CA: Jossey-Bass.

Smircich, L. (1983) Concepts of culture and organizational analysis. Administrative Science Quarterly, 28,3, 339-58.

Wajcman, J. (1998) Managing Like a Man. Cambridge: Polity Press. 
Webb, J. (1997) The politics of equal opportunity. Gender, Work E Organization, 4,3, 159-69.

Wickham [Correction made here after initial online publication.], J., Collins, G., Greco, L. and Browne, J. (2008) Individualization and equality: women's careers and organizational form. Organization, 15,2, 211-231.

Woodall, J., Welchman, R. and Edwards, C. (1997) Organizational restructuring and the achievement of an equal opportunity culture. Gender, Work E Organization, 4,1, 2-12. 